\title{
Notas
}

\section{A Europa atual: questões de segurança coletiva e integração econômica}

\author{
ARTHUR V. CORRÊA MEYER
}

I)

A Europa Ocidental do presente se defronta com importantes problemas de segurança coletiva e de integração econômica com o resto do continente. A análise dessas questões diz respeito não somente à problemática européia propriamente dita, mas também à Aliança Atlântica, representada pela Organização do Tratado do Atlântico Norte (OTAN).

A Aliança Atlântica, hoje com 50 anos de existência e abarcando dezessete países da Europa Ocidental (todos, com exceção de Irlanda, Suécia, Finlândia, Suíça, Áustria e dos Microestados europeus), bem como os Estados Unidos da América (EUA) e o Canadá, procura redefinir sua identidade no contexto internacional vigente após o término da confrontação Leste-Oeste. Passo importante nesse sentido foi a constituição, em meados de 1997, do Conselho de Associação Euro-Atlântico (CAEA), reunindo basicamente os membros da OTAN e os países integrantes ou da esfera de influência direta da antiga União Soviética (convidados pelos EUA a formar o chamado Partnership for Peace).

Também em meados de 1997, ocorreu a primeira grande transformação da OTAN (em termos de sua composição) na era pós-Guerra Fria, com o convite feito a Polônia, Hungria e República Tcheca para ingressar na entidade, (o que se veio a consumar em março de 1999). A questão do alargamento da OTAN, por suas profundas implicações sobre a paz e a segurança da Europa, ainda suscita, no entanto, várias controvérsias nos dois lados do Atlântico.

De modo geral, os países europeu-ocidentais consideram necessária a expansão da OTAN com vistas a abarcar a região da Europa Central, que lhes parece, por razões geopolíticas, de importância crucial para sua segurança. Daí decorre a recente decisão de admitir na Organização Polônia, Hungria e República Tcheca, com a perspectiva de adesão, em futuro relativamente próximo, de Romênia, Áustria e Eslovênia. 
Por outro lado, mesmo entre países europeu-ocidentais membros da Aliança Atlântica, inexiste consenso quanto ao eventual alargamento da OTAN de modo a abarcar outros países balcânicos e os Estados do Mar Báltico, os quais não lhes apresentariam interesses vitais de segurança semelhantes aos região da Europa Central. Além disso, esses países do ocidente europeu ficariam temerosos de antagonizar ainda mais a Rússia (a qual já manifestou desagrado com a decisão, tomada em 1997, de admitir na OTAN Polônia, Hungria e República Tcheca) com essa possível expansão adicional da Aliança Atlântica, criando um foco maior de tensão e atrito no continente.

Nos EUA, também, tem havido divergências sobre o mesmo assunto, manifestadas por correntes de opinião lideradas, de um lado, por George Kennan (o homem que contribuiu decisivamente para a formulação da política de containment contra a ex-União Soviética, no início da Guerra Fria ) e pelo exSecretário de Estado Henry Kissinger. A primeira corrente é contrária à expansão da OTAN, por achar que causará alarme na Rússia, aí fortalecendo suas forças antidemocráticas; constituirá fator de dissensão no continente europeu; e, pelo seu custo financeiro, reduzirá a capacidade de a Organização cumprir eficientemente sua missão primária. Por seu turno, a segunda corrente defende o alargamento da OTAN, invocando o argumento de que essa medida é essencial para impedir qualquer futura ameaça militar de uma Rússia ressurgente contra a Europa e a América do Norte.

Essas divergências ficaram, em parte, refletidas no summit da OTAN, realizado em Madri, na Espanha, em julho de 1997, quando ocorreu marcada diferença de pontos de vista entre os EUA e alguns países da Europa Ocidental (liderados pela França) acerca do alargamento da Organização. Nessa ocasião, como se viu, decidiu-se admitir na OTAN apenas três países novos (Polônia, Hungria e República Tcheca), mas a França e alguns países aliados propugnaram, também com vigor, pela admissão da Romênia e da Eslovênia, as quais, embora sem alcançar sua pretensão, receberam manifestações de encorajamento quanto à futura possibilidade desse objetivo.

Na verdade, a questão do alargamento da OTAN envolve uma delicada composição de interesses entre os EUA, a Europa Ocidental e a Rússia. Na visão predominante dos países ocidentais, a expansão da Organização é necessária para garantir a paz e a estabilidade no continente europeu e dificultar ou impedir uma eventual ressurgência do expansionismo russo; ao mesmo tempo, entretanto, esse alargamento deveria ser feito gradualmente (em razão, sobretudo, dos seus custos financeiros) e com cuidado, de modo a não alienar os países incapazes de ser admitidos a curto prazo e a não criar no Governo de Moscou uma sensação de cerco e exclusão, estimulando o crescimento de tendências ultra-nacionalistas e belicosas naquele país, ainda muito poderoso militarmente (embora, no momento, enfraquecido economicamente). 
Várias possíveis abordagens têm sido propostas para a estratégia da expansão "gradativa e cautelosa" da OTAN. Todas elas procuram, em maior ou menor medida, "conservar a porta aberta" aos candidatos a ingressar na Organização e, simultaneamente, manter boas relações com os países da ex-União Soviética (sobretudo Rússia e Ucrânia) sem lhes dar direito de veto sobre as grandes decisões da entidade.

A primeira linha de ação proposta, a qual tem constituído a política oficial do presente Governo americano, consiste na chamada open door policy: o ingresso na OTAN estaria aberto, em princípio, a todos os participantes do Partnership for Peace, agora agrupados no CAEA. Os pretendentes a ingressar na Organização (inclusive a própria Rússia) teriam de declarar explicitamente sua candidatura e lutar pela sua aprovação junto aos países membros.

A segunda abordagem à questão do alargamento da OTAN poderia ser denominada de parallel expansion, consistindo em igualar a lista de candidatos ao ingresso na OTAN àquela de pretendentes à admissão na União Européia (UE). Estariam enquadrados nessa categoria, além de países que já são membros da UE (Irlanda, Suécia, Finlândia e Áustria), a Suíça (Estado tradicionalmente neutro); as pequenas repúblicas bálticas (Estônia, Letônia e Lituânia); países da Europa Central, balcânica e mediterrânea (Eslováquia, Eslovênia, Romênia, Bulgária, Macedônia, Albânia, Croácia, Bósnia-Herzegovina, Iugoslávia, Chipre e Malta); e, até mesmo, os Microestados (Andorra, Mônaco, San Marino e Liechtenstein).

A terceira alternativa, que se poderia chamar de "minimalista”, prega um alargamento da OTAN limitado exclusivamente a alguns poucos países, cuja posição geográfica seria de vital importância para a defesa da Europa Ocidental. Diante da recente decisão de admitir na Organização Polônia, Hungria e República Tcheca, poderiam, então, nela ingressar Áustria, Eslováquia e Eslovênia, bem como, eventualmente, Suíça, Finlândia, Suécia, Irlanda e, talvez (com menor probabilidade), as pequenas repúblicas bálticas.

A primeira linha de ação (e também, em certa medida, a segunda) teria o inconveniente de permitir uma expansão demasiadamente ampla da OTAN, a qual poderia vir a sofrer um processo de virtual paralisia na tomada ou implementação de decisões. Nesse caso, a Organização ficaria ameaçada de perder eficácia por sua abrangência muito extensa, tal como ocorreria hoje, de certa forma, com a Organização de Segurança e Cooperação da Europa (OSCE).

A segunda abordagem (a chamada parallel expansion), além de possibilitar um alargamento ainda relativamente amplo da OTAN, não é atraente para os EUA (nem para alguns países europeu-ocidentais importantes) pelo fato de excluir abertamente a Rússia, bem como outros Estados que nasceram com o fim da antiga União Soviética. Essa exclusão, apesar de favorecer a eficácia interna da Organização com relação à primeira abordagem, poderia constituir um foco de atrito permanente, que não interessa ao Governo de Washington (o qual não deseja, 
tampouco, que a estratégia da OTAN seja dominada por critérios próprios unicamente à UE).

Por fim, a terceira alternativa básica para a expansão da OTAN (o enfoque “minimalista”), embora de mais fácil implementação, seria de difícil justificação política, levando os países excluídos (sobretudo os balcânicos e os bálticos) a se sentir moralmente rejeitados. Isso poderia ensejar o surgimento de crises internas nesses países excluídos a priori com reflexos desestabilizadores para a paz e a segurança em todo o continente europeu.

Do ponto de vista da OTAN como um todo e, principalmente, do seu membro mais poderoso e influente, os EUA, nenhuma das três alternativas expostas anteriormente é inequivocamente a melhor. Dessa forma, nos próximos anos, a Aliança Atlântica deverá, possivelmente, continuar adotando um meio termo entre conservar aberta a possibilidade de alargamento, manifestando aos países da exUnião Soviética e do antigo Pacto de Varsóvia intenções amistosas, e recusar novas admissões em massa na Organização.

A linha de conduta descrita acima se discerne pelos resultados do summit da OTAN em Madri, em julho de 1997. Nessa ocasião, não somente se decidiu admitir na Organização os três novos membros já referidos, como também foi assinado acordo de cooperação política e militar com a Ucrânia (semelhante a instrumento firmado com a Rússia no mês anterior). Os referidos acordos com a Rússia e a Ucrânia prevêem a manutenção de consultas regulares (pelo menos, duas vezes por ano) e cooperação na luta contra o terrorismo e o narcotráfico.

O gradualismo e a cautela na expansão da OTAN se explicam não apenas pelo desejo de "acalmar" os países da ex-União Soviética, como também pelos altos custos financeiros envolvidos, em termos de ampliação da infra-estrutura de transportes e comunicações, adaptação e padronização de equipamentos militares dos novos membros e preparação de novas rapid-reaction forces. A título exemplificativo, pode-se citar que, no início de 1997, um estudo elaborado pelo Pentágono americano calculou o custo da primeira rodada de alargamento da OTAN em torno de US\$ 30 bilhões ao longo de treze anos.

A OTAN se defronta ainda com o desafio de reformar sua estrutura militar para adaptá-la à era pós-Guerra Fria, o que envolve, principalmente, uma redivisão dos seus comandos. Alguns países europeus, a começar pela França, têm reivindicado maior compartilhamento de poderes, nas esferas política e militar da Organização, entre os EUA e a Europa. A questão do burden sharing, ou seja, da divisão dos ônus financeiros, entre os EUA e os demais países membros, para manter a OTAN, continua também importante.

A crise política e militar na província iugoslava de Kosovo, agudizada a partir de março de 1999 com o início dos bombardeios aéreos pelos países membros da OTAN, tornou ainda mais complexo o quadro anteriormente descrito. A intervenção militar realizada na Iugoslávia pelos países da Aliança Atlântica, 
liderados pelos EUA, constitui iniciativa sem precedentes e cujo desfecho pode ter conseqüências graves e imprevisíveis.

II)

À semelhança do que ocorre com a OTAN, sérios dilemas quanto a seu futuro hoje enfrenta a UE. O processo de integração econômica da Europa Ocidental, iniciado com a Declaração Schuman em 1950 e hoje envolvendo 15 países, tem sido indiscutivelmente bem sucedido, mas observa-se dificuldade na formação de consenso quanto aos rumos vindouros da entidade.

O Tratado de Maastricht estabeleceu, há poucos anos, metas ambiciosas para a integração política, econômica e social dos países agrupados na UE. Dentre essas metas estavam a Política Externa e de Segurança Comum (PESC), bem como a União Econômica e Monetária (UEM), com o estabelecimento de uma moeda única (o “euro”), iniciando-se em 1º de janeiro de 1999.

Reunidos em Amsterdã, na Holanda, em junho de 1997, os representantes dos Governos nacionais da UE aprovaram algumas revisões ao Tratado de Maastricht, em seguimento à Conferência Intergovernamental de Turim do ano anterior. As emendas então aprovadas foram, no entanto, de caráter e alcance reduzidos, em conseqüência das dificuldades já mencionadas sobre a formação de consenso quanto ao futuro da UE.

No tocante à PESC, decidiu-se apenas que o Conselho Europeu procurará definir normas gerais e ações a serem tomadas em áreas onde os países-membro têm interesses comuns importantes. As decisões nesse campo serão tomadas por unanimidade, mas se permitirá a um país-membro recorrer eventualmente a uma “abstenção construtiva” que o exclua de uma iniciativa, sem bloquear a atuação dos demais.

Foi ainda aprovado que o Conselho Europeu procure definir uma política de defesa comum dentro de uma "perspectiva européia". Diversas questões ficaram, porém, em aberto, entre elas, a do status da União da Europa Ocidental (UEO) - aliança militar que congrega os países-membro da UE (com exceção da Áustria, Suécia, Finlândia, Irlanda, Grécia e Dinamarca) em relação à União Européia.

As dificuldades sentidas pela UE para fazer avançar a PESC são de diversas ordens. Em primeiro lugar, diferentes concepções se encontram em discussão e nenhuma delas encontrou ainda aceitação generalizada. O problema do relacionamento com os EUA também continua presente, uma vez que o Governo de Washington tende a criticar a UE por, freqüentemente, não conseguir falar em uníssono em termos de política externa e de defesa e a não considerar seriamente manifestação da UE nesse campo, quando expressa pela Comissão Européia ou por algum Estado pequeno que ocupe a presidência (rotativa) do Conselho Europeu. 
Desde a Conferência Intergovernamental de 1996, quatro diferentes alternativas para a PESC vêm sendo debatidas. A primeira, apresentada pela Finlândia e pela Suécia, restringe as metas de defesa comum da UE a operações de caráter humanitário (evacuações supervisionadas por militares, manutenção de paz e gerenciamento de crises): nesse caso, todos os membros da UE disporiam de iguais direitos para decidir e tomar parte nessas operações (a serem possivelmente executadas pela UEO), enquanto à OTAN caberia a responsabilidade por missões de combate, caso necessário.

Uma segunda alternativa, proposta sobretudo pela França , consistiria em tornar a UEO o "braço armado" da UE, a qual poderia, então, implementar direta e plenamente sua política de defesa. Alguns países-membro da UE não fazem parte, entretanto, da UEO e, a curto ou médio prazos, essa alternativa necessitaria do recurso à OTAN para a execução de missões de combate, enfraquecendo seu caráter de iniciativa genuinamente européia.

Outra alternativa para a PESC, que foi proposta pelo Reino Unido, seria a de manter inalterados os arranjos institucionais existentes. Nesse caso, a UE poderia tão somente solicitar à UEO a execução de ações militares, das quais poderiam participar qualquer país europeu membro da OTAN (a ser decidido caso a caso).

Igualmente conservador é o approach da quarta e última alternativa para a PESC, a qual consistiria em fundir completamente a defesa européia na estrutura da OTAN. Tal como a precedente, essa alternativa descaracteriza o aspecto europeu da política externa e de defesa da UE, sendo, por isso, pouco aceitável para a França e os "euro-entusiastas".

Todo o debate acerca do PESC no seio da UE também envolve uma reflexão renovada sobre as políticas nacionais de defesa dos países da Europa Ocidental, sobretudo alguns dos mais importantes, como o Reino Unido e a França, que são membros permanentes do Conselho de Segurança da ONU. Esses países hoje procuram reorganizar suas forças armadas, dentro de uma concepção integrada de defesa, visando a manter uma capacidade de atuação eficaz em teatros de operação distantes.

É real a ameaça, cada vez mais sentida pelos países da Europa Ocidental, representada pela proliferação das tecnologias de mísseis balísticos e das armas de destruição em massa (nucleares, químicas e biológicas). Essas tecnologias vêmse tornando disponíveis no mercado internacional, graças a exportações realizadas sobretudo pela Rússia e pela China: alguns países da Ásia meridional, Oriente Médio e norte da África, cujo relacionamento com a Europa Ocidental é potencialmente conflituoso, têm adquirido essas tecnologias.

Em particular, para a Europa Ocidental, constitui motivo de especial e cuidadosa atenção a Rússia, país hoje que se assemelha fortemente à Alemanha da República de Weimar, na década de 1920 (com democracia fraca, economia abalada e insatisfação generalizada). A UE e a OTAN não se dispõem a dar ao 
Governo de Moscou o reconhecimento de uma esfera de influência própria da Rússia e esta, por sua vez, tende a considerar insuficiente o que lhe vem sendo oferecido pelos países ocidentais (diálogos e parcerias de cooperação).

A subida ao poder da coligação de partidos social-democrata e verde (tradicionalmente pacifista) na Alemanha, liderada por Gerhard Schroeder, em outubro de 1998, introduziu um elemento adicional de complexidade às questões de defesa e de política externa na Europa Ocidental. Desenha-se a possibilidade de que a UE, dividida por opiniões diferentes quanto ao escopo da PESC, venha a ser tentada a adotar uma mentalidade isolacionista em política externa, a qual, além de ineficaz no mundo crescentemente globalizado, poderia torná-la caudatária dos EUA.

Por outro lado, a recente intervenção militar da OTAN na Iugoslávia, ainda em curso, se bem que contando com respaldo político da UE, não deixa de evidenciar uma certa fraqueza desta última. Com efeito, a UE continua sendo um "gigante econômico" e um "anão político e militar”, "ainda necessitando do apoio (se não, da liderança) dos EUA para levar a cabo uma operação externa de grandes proporções envolvendo suas forças armadas”.

III)

Se, no campo da PESC, há divergências sobre a concepção e dificuldades de implementação, no campo econômico, também, existem problemas no seio da UE. A consecução da ambiciosa meta representada pela União Econômica e Monetária (UEM) é prejudicada pelo grave problema do desemprego que, hoje, afeta vários países europeus, a começar pela França e pela Alemanha (nos quais a taxa é superior a $10 \%)$.

Para a instituição da UEM, com o estabelecimento da moeda única e de um Banco Central Europeu (já em funcionamento desde junho de 1998) foi requerida a satisfação, por parte dos países membros da UE, dos chamados "critérios de Maastricht” de desempenho econômico. Esses critérios impõem, primeiramente, a cada país que deseje aderir à UEM a apresentação de um déficit público total não superior a 3\% do seu Produto Interno Bruto (PIB) e uma dívida pública total de, no máximo, 60\% do PIB.

Os “critérios de Maastricht” também incluem outras metas de convergência, relativas a taxa de inflação, taxa de juros de longo prazo e taxa de câmbio. Por enquanto, 11 países da UE participam da UEM desde $1^{\circ}$ de janeiro de 1999, ficando de fora (mais por vontade própria) o Reino Unido, a Suécia e a Dinamarca; e, também (por não satisfazer os “critérios de Maastricht”), a Grécia.

Apesar de a maioria dos países membros da UE hoje satisfazerem os critérios de convergência para o estabelecimento da UEM, existem percepções 
diferentes acerca da linha de conduta a ser seguida pelo Banco Central Europeu (BCE) e do seu relacionamento com os Governos nacionais e seus bancos centrais (até 2002, quando o "euro” entrará fisicamente em circulação, substituindo completamente as moedas nacionais dos participantes). A UEM se encontra ameaçada pelo risco de que os Governos nacionais de seus países-membro recorram a políticas assimétricas para lidar com os sérios problemas do desemprego (já referido acima) e da reforma dos sistemas de previdência social. A presente conjuntura da economia mundial, caracterizada por estados de recessão na Rússia, na Ásia e, em certa medida, na América Latina, contribui para reforçar o mencionado risco.

As considerações precedentes guardam especial relevância para a atuação do BCE: os 11 países-membro da UEM deverão apresentar crescimento médio de apenas 2\% em 1999 (estimativa de Deutsche Bank) e, no fim de 1998, o número de desempregados na UE subia a 17 milhões. Isso deverá requerer uma administração muito cuidadosa das políticas monetárias (coordenadas pelo BCE) e fiscais dos países-membro da UE.

A meta da UEM é indiscutivelmente ambiciosa, representando um estágio de integração econômica superior ao do mercado comum. A consecução desse objetivo requer um grau ainda mais elevado de homogeneidade entre os países membros e, portanto, maior esforço de coordenação de políticas econômicas. Seus benefícios serão, por outro lado, consideráveis, reduzindo custos de transação e eliminando o risco das flutuações de taxas cambiais sobre o comércio e os fluxos de capitais, o que permitirá a criação de condições para um surto renovado de crescimento e prosperidade nas economias da Europa Ocidental.

Parece cada vez mais claro que, para a UEM poder ser plenamente implementada a curto prazo com sucesso, será necessário aos países da UE adotar amplas reformas conjuntas de suas legislações trabalhistas e de seus sistemas de previdência social. A UEM retirará dos Governos nacionais os ajustamentos das taxas cambiais como instrumento de política econômica, criando novas pressões sobre os (já relativamente pouco flexíveis) mercados de trabalho: daí decorre a necessidade de assegurar maior flexibilidade aos salários e contratos laborais nos países da UE, mas as iniciativas nesse sentido ainda são geralmente poucas e de alcance limitado.

De qualquer forma, a criação do “euro" deverá constituir a maior transformação do sistema monetário internacional dos últimos trinta anos. Caso baseado em uma política monetária consistente, o “euro” se tornará a segunda mais importante moeda de reserva do mundo, rivalizando com o dólar norteamericano. O grande peso econômico da UE, a qual, em 1996, detinha cerca de 20\% do PIB mundial (as participações dos EUA e do Japão eram, respectivamente, de $20 \%$ e de $8 \%$ ), bem como quase $15 \%$ do comércio mundial de mercadorias, 
dará condições ao “euro" de desempenhar papel semelhante ao dólar dos EUA como moeda internacional.

IV)

A UE também enfrenta sérios desafios quanto à reforma de sua estrutura institucional e à admissão de novos países-membro da Europa Central e Oriental. O problema do chamado "deficit democrático" (expressão usada para designar certa deficiência de accountability dos órgãos executivos da UE, a começar pela Comissão Européia, em relação aos eleitorados dos países-membro) continua causando mal-estar. As mudanças aprovadas a esse respeito na reunião de cúpula de Amsterdã, em junho de 1997, foram ainda reduzidas, especialmente no tocante às atribuições do Parlamento Europeu, cujos poderes continuam algo limitados.

Em março de 1999, ocorreu sério problema institucional dentro da UE, com a renúncia coletiva dos membros da Comissão Européia, após divulgação de relatório elaborado por técnicos e auditores contendo severas críticas à sua gestão administrativa e financeira. Esse fato inusitado pôs novamente em evidência o problema do "déficit democrático" na UE: espera-se que a recente eleição a do ex-Primeiro Ministro italiano Romano Prodi (político de grande prestígio) para a presidência da Comissão Européia, sirva para o encontro de soluções para essa questão.

No que se refere à admissão na UE de novos países membros, Polônia, Hungria e República Tcheca são os que apresentam maiores possibilidades a curto prazo, uma vez que Suíça, Noruega e Islândia, por razões de política interna, não demonstram grande interesse no assunto. Considera-se, ainda, que a Estônia, a Eslovênia e o Chipre poderiam também formar, com os três países mencionados acima, a primeira leva de novos membros da UE; a segunda leva seria formada por Letônia, Lituânia, Eslováquia, Romênia e Bulgária.

É clara a necessidade de alargamento da UE, para fundar, em bases sólidas, a liberdade política e econômica no continente europeu. Apesar disso, o processo de admissão de novos membros da Europa Central e Oriental tem sido prejudicado por várias dificuldades, não somente na área do comércio (especialmente dos produtos agropecuários, por causa da Política Agrícola Comum da UE), como também pelo fato de que isso acarretará diminuição dos recursos dos fundos de desenvolvimento comunitário para os seus maiores recipiendários atuais (Espanha, Grécia, Portugal, Irlanda, Bélgica e Luxemburgo, os quais recebiam juntos em 1998 cerca de ECU\$ 18 bilhões anualmente).

Tanto no âmbito da OTAN, quanto no da UE, a Europa hoje se defronta com dilemas e desafios. A incorporação dos países da antiga "cortina de ferro" ao mainstream europeu parece estar caminhando mais rapidamente na área militar 
(esfera da OTAN) do que na área econômica (esfera da UE), quando o desejável pareceria ser o oposto, tendo em vista a situação relativamente instável que se observa na ex-União Soviética, em geral, e na Rússia, em particular. Por outro lado, não há dúvida de que é ainda muito significativa a capacidade européia de contribuir positivamente à paz internacional e de influenciar sobre o crescimento da economia mundial.

Abril de 1999 